\title{
Cultivation Mode and Practice of Master Teaching Based on Cooperative Education of "Production, Study and Research" _ A Case Study of Vehicle Engineering
}

\author{
Na Yang ${ }^{1,2^{*}}$, Jianfeng Wang ${ }^{1,2}$, Dongwei Liu ${ }^{1,2}$ \\ ${ }^{1}$ School of Automotive Engineering, Harbin Institute of Technology (Weihai), Weihai 264209 \\ ${ }^{2}$ China Automotive Technology and Research Center Co.Ltd., Tianjin 300300 \\ *Corresponding author: ynhelen@163.com
}

\begin{abstract}
With the rapid development of China's economy and society, there is an urgent need for a large number of highlevel professionals with innovative, entrepreneurial and practical abilities. According to the cooperative education of production, study and research of Harbin Institute of Technology, the advantages and disadvantages were introduced and analyzed, and suggestions for improvement were put forward. Based on the implementation of the "two-stage" training mode and the "two mentors" guidance system, it is necessary to establish and improve the efficient training system and improve the sense of responsibility and participation of enterprises, so as to make the cooperative education of production, study and research more mature and perfect, and improve the professional level of graduate students and enhance the competitiveness of employment.
\end{abstract}

Keywords: "production, study and research"; vehicle Engineering; graduate student; cooperative education.

\section{校企双导师制下的研究生联合培养模式研究}

\author{
杨娜 1,2 , 王剑锋 1,2 ，柳东威 1,2 \\ 哈尔滨工业大学 (威海) 汽车工程学院 威海 264209; \\ 2 中国汽车技术研究中心有限公司 天津 300300
}

\section{摘要:}

随着我国经济社会的快速发展, 迫切需要大批具有创新能力、创业能力和实践能力的高层次专门人才。 根据哈尔滨工业大学 “产学研” 联合培养项目的实践情况, 介绍并分析了目前联合培养模式的优缺点, 并提出了改进建议。认为在实施 “两段式” 培养方式和 “双导师” 指导制度的培养模式基础之上，需 要进一步建立健全高效培养体系以及提高企业责任心和参与度，使 “产学研” 联合培养模式更加成熟 和完美，提高研究生专业水平和增强就业竞争力。

关键词: 产学研; 车辆工程; 研究生; 联合培养

\section{1. 前言}

一直以来, 我国研究生人才培养都是以高校环境培 养为主, 但随着高等教育大众化、知识经济时代和科技 的加速发展, 单一高校研究生培养模式已不能适应研究 生教育和社会的发展, 研究生在培养方式上需要进行相 应的改革, 满足社会对高技术人才的需求。目前, 在研 究生培养模式中, 基于产学研联合的教育培养模式是未 来研究生教育的重要发展趋势, 也是有效提升研究生创
新水平和实践能力、满足企业技术创新需求的重要途径。 产学研联合模式是把研究生教育、科研和生产三种行为 相结合, 充分发挥高校、企业和科研院所等部门的优势, 实行校企协调育人机制, 为研究生提供一直接参与实际 工程和科学问题的机会, 提高研究生的创新水平和实践 能力。

目前的研究生培养, 由于经费、资源和体制的制约, 以及车辆工程专业研究生规模的不断扩大, 存在实践教 学弱化、实践师资不足、实践场所缺乏、研究生学习和 研究的内容与生产实际需求脱节, 导致许多研究生实践 
动手能力弱、技术管理能力欠缺, 难以适应实际工作。 因此, 深化车辆工程专业研究生教育改革, 调整培养目 标, 创新培养方法, 探索一条服务于国家战略目标的高 层次应用型人才培养模式势在必行。

\section{2. “产学研” 联合培养模式之简介}

“产学研” 联合培养的方式是充分利用学校及社会 资源培养出适应行业发展需求的高素质人才的培养方 式。由各高校负责的全日制专业研究生的教育培养中, 侧重于专业理论与科研创新方面的深度挖掘, 而企业在 相关方向上的研究更注重于最大化实现理论, 偏向于实 际应用。校企间的合作培养可实现高素质人才培养的全 面化、实用化和综合化。

虽然 “产学研” 联合培养具有许多优势, 但就目前 来讲, 该模式的推动仍存在着许多困难。比如, 产学研 联合培养规模不大, 合作效益不够明显; 产学研合作各 方权责不太明晰, 合作难以持续深入; 产学研联合缺乏 有力的政策保障, 合作缺乏持续动力等多方面问题 ${ }^{[1]}$ 。 同时, 也有研究指出, 当前产学研联合培养研究生由于 观念转变不到位、配套政策体系不完善、体制机制不健 全等原因, 合作优势尚未得到有效体现 ${ }^{[2]}$ 。

\section{3. “产学研” 联合培养模式之探索}

“产学研” 联合培养模式的具体实施要结合各高校 不同的培养方案进行。以哈尔滨工业大学 (威海) 车辆 工程专业为例, 学校产学研协同联合培养研究生主要采 取 “两段式” 的培养方式。把整个培养阶段分为学校的 基础理论夯实和企业实践研究两个阶段。第一学年研究 生主要在学校完成理论学习, 第二学年起研究生通过参 与实践项目完成论文选题及应用研究。为了充分尊重研 究生的学习及研究意愿, 并保障研究生学习的完整性, 学校将结合企业的需求, 通过双向选择, 让研究生参与 项目研究, 将理论学习融入实践应用中, 构建一种实践 引领的研究生培养方式。这是 “学习一实践一开发” 相 联系、理论实践相结合的教育模式, 是培养具有较强实 践能力的、应用型、开发性高级专门人才的有效途径。

在 “两段式” 培养过程中, 研究生将分别处于高校 导师和企业负责人的管理之下。目前我国的高校教师, 特别是青年教师, 无论是国内高校的毕业生还是海外高 校的毕业生, 大部分是学术型硕士或者博士, 不具备企 业工作经验, 相对缺乏工程实践经历 [3]。大多数企业导 师缺少指导研究生的教学经验, 这不仅会影响研究生的 培养质量, 也会影响他们对研究课题的选择与把握。因 此, 把导师个人培养为主导的学徒式研究生指导制度拓 展为跨学科协作的 “双导师制” 模式十分有必要, 这不 但可以扩大研究生的知识面, 还有利于培养创新型人才 [4], 尤其是有利于培养车辆工程专业需要的复合型应 用人才。

另一方面, 由于激励机制的缺失, 企业导师往往将
对研究生的指导视为企业与高校分派给自己的额外任 务, 从而产生消极抵触情绪。并且, 由于担心技术泄密、 研发过程中断等风险, 企业导师让研究生参加企业项目 开发的意愿较弱。因此, 必须形成一套企业导师管理与 激励制度, 解除企业导师的后顾之忧, 调动其积极性, 将形式上的指导转变为实质上的指导。在这方面, 哈尔 滨工业大学（威海）车辆工程专业导师会承诺向企业持 续推荐优质人才, 并积极鼓励研究生参与相关的校企合 作项目, 初步了解企业的工作模式和研究水平, 而企业 也将学生作为公司新一代工程师仔细培养, 以此推进专 业学位研究生培养与用人单位实际需求的紧密联系, 积 极探索人才培养的供需互动机制, 达到了双赢的局面。

\section{4. “产学研” 联合培养模式之初步成效}

在哈尔滨工业大学 (威海) 车辆工程专业“产学研” 联合培养项目实施的第一年，专业内派出总人数的 $25 \%$ 的同学参与, 涵盖“学术型研究生”和“专业型研究生”, 合作企业主要是中国汽车技术研究中心等国内大型汽 车技术研究机构。这部分研究生的学位论文选题均来源 于企业合作的应用课题, 以突破企业关键技术来命题, 强化工程实践能力培养。企业导师与校内导师共同把握 研究生的研究方向, 共同确定研究生的论文选题, 确保 全日制专业学位研究生的论文研究与工程实践紧密结 合。通过论文工作, 不仅提高科研工作水平, 而且解决 企业的实际问题, 增强研究生工程实践能力。

此外, 用人单位对学校专业学位研究生培养质量的 满意度和接受度也在不断提高。通过校企联合培养的研 究生除了在科学研究上具备了过硬的积累, 又同时在专 业实践上具有了充足的准备, 使他们及早地了解了专业 工作的具体内容及要求等, 从而在正式入职以后, 能确 保尽快熟悉工作内容。以车辆工程学科为例, 该学科是 学校的优势学科, 在修订专业学位研究生培养方案时, 根据行业对人才知识与能力的需求, 制定相对全面的课 程体系, 设立模块必修课, 实行模块式培养, 再结合企 业的实践培养, 为相关院校及学科的研究生实践基地建 设起到了示范作用。

\section{5. “产学研” 联合培养模式之思考与启发}

全日制专业学位研究生有着和工学硕士研究生同 样的起点, 也会有学院式教育的不足, 产学研合作教育 模式是把以课堂传授知识为主的学校教育与直接获取 实际经验、实践能力为主的生产、科研实践有机地结合 在一起。通过哈尔滨工业大学 (威海) 车辆工程专业的 “产学研” 联合培养实践, 虽然有许多成功的经验和可 喜的成绩, 也还需要我们坚持不断地探索和追求。

\section{1 提高高校联合培养体系}

首先要加大产学研合作教育宣传, 注重导师们教学 
思想和观念的转变。让导师明确其责任应主要体现在人 才培养的质量与水平上, 而不是片面追求科研成果。同 时认识到产学研联合培养研究生是培养高素质应用创 新人才、提高教育质量的有效途径, 其不仅能提高研究 生的就业竞争力, 导师还能通过与企业人员的交流, 获 得更多与社会接触的机会, 既有助于加快科研成果转化, 又为科学研究指明了方向。此外, 通过鼓励高校导师和 企业导师共同申请课题的方式, 允许高校导师参与企业 咨询、企业顾问委员会等工作, 充分肯定其工作的价值, 给予合理的评价以及相应待遇、报酬, 并把开展联合培 养工作作为评选优秀研究生导师的参考, 使高校导师成 为连接大学和企业的枢纽, 以此来开展产学研联合培养 工作。

研究生是产学研联合培养的参与者, 研究生的积极 性决定了产学研联合培养这一模式能否成功的关键之 一。因此, 高校应引导研究生树立正确的产学研联合培 养观念, 区分联合培养和生产实习的区别, 使研究生将 培养目标放在自身能力的全面提升方面, 让学生们认为 联合培养是一个值得把握和竞争的机会。与此同时, 各 高校在在设计评价指标体系中, 要充分考虑产学研联合 培养研究生的应用性和创新性特点、企业的评价标准等 因素, 遵循科学性、可行性、发展性、全面性、准确性 和可操作性原则, 提高研究生实际工作能力和综合素质 指标的比重, 进一步调动学生参与积极性。

\section{2 提高企业参与度和责任心}

企业必须增强社会责任感, 要充分认识到支持和积 极配合高校进行产学研联合培养是企业应当承担的责 任和义务。虽然企业不能获得短期利益, 但是通过与高 校的联系, 企业既能利用高校的人才和智力优势, 解决 企业生产过程中存在的实际问题, 又能为企业培养、引 进和储备人才, 有利于提高企业的劳动力素质, 推动企 业可持续发展，因此企业更应该关注其带来的长远利益。

其次, 对企业导师进行及时的考核、沟通与反馈, 是检验企业导师是否发挥了其应有的作用, 促使企业导 师不断改进和提升其工作绩效的重要方法。考核可采用 自我评价和他人评价相结合的方式, 他人评价包括联合 培养研究生、企业和高校, 主要从企业导师的道德品行、 有效沟通、团队合作、指导技能、发展联合培养研究生、 联合培养研究生的科研成果和实践能力等几方面进行 考核。

最后, 企业应对联合培养研究生有一系列完整的培 养方案, 包括每一阶段的时间、要求、内容等, 并在每 阶段结束后, 检查、考核联合培养研究生的进度, 提出 具有指导性的意见 $[5]$ 。

\section{6. 结束语}

“产学研” 联合培养模式使研究生教育由高校得以 向社会延伸, 而社会的有效资源则为高校培养高层次
创新型人才提供了肥沃的土壤。参与哈尔滨工业大学 (威海) 车辆工程专业 “产学研” 联合培养项目的研究 生在科研见识的提升、毕业设计的深度以及个人竞争力 的提高等方面均有些许优势，这说明 “产学研” 联合培 养的教育方法值得大力推广。而面对推广道路上的种种 问题则需要研究生培养单位在实践中去积极探索和不 断总结, 随时公开产学研相结合的教育的相关的教学改 革研究成果, 这可以让教学改革的成果得以共享、应用、 继承和改进, 为提高研究生教育水平积累经验, 为产学 研相结合的教育日致完善铺路。

\section{作者简介:}

杨娜，女，1982 年 1 月生，山东淄博人，哈尔滨工 业大学 (威海) 汽车工程学院车辆工程系主任, 博士, 副教授, 硕士生导师, 通讯地址: 山东省威海市文化西 路 2 号 哈工大 (威海) 研究院 1\#南 101, 邮编 264209, 电话：0631-5677530,18561273381。

\section{项目基金}

项目来源：哈尔滨工业大学研究生教改项目

(编号：JGYJ-2018047)

\section{REFERENCES}

[1] Sun Yuedong, Luo yaocheng, Liu yuan. The problems and reform suggestions of the mode of combination of production, teaching and research. Science \& Technology Progress and Policy, 2010(27):135-137.

[2] Gao Xingwu, Hu yong. The current situation, problems and countermeasures of the joint cultivation of graduate students by Industry University Research Institute in Beijing--Based on the questionnaire analysis. China Higher Education Research, 2010(11):42-46.

[3] Gan Qin, Bai Wei. Service for special needs, career orientation and innovation of cultivation mode for master of engineering degree--Practice and exploration of "2461" postgraduate training mode of Chongqing University of science and technology. Academic Degrees \& Graduate Education, 2014(8):14-18.

[4] Zhao Feng. Research on the reform and Innovation of postgraduate training mode. Journal of Yangzhou University (Higher Education Study Edition), 2007,11(24):91-83.

[5] Yu Jiaqi. Research on the Mode and Operational Mechanism of Industry-University-Research Cooperative Education. East China Normal University,2011. 